\title{
Knowledge, Attitudes and Practices Related to HIV Stigma and Discrimination Among Healthcare Workers in Oman
}

Samir Shah, ${ }_{1}^{1}$ Ali Elgalib, ${ }^{1}$ Adil Al-Wahaibi, ${ }^{2}$ Maha Al-Fori, ${ }^{1}$ Prasanna Raju, ${ }_{1}^{1}$ Mahmood Al-Skaiti, ${ }^{3}$ Huda N. Al-Mashani, Kishor Duthade, ${ }^{3}$ Iyad Omaar, ${ }^{3}$ Muhammad Muqeetullah, ${ }^{3}$ Nilanjan Mitra, ${ }^{3}$ Parag Shah, ${ }^{3}$ Mohammed Amin, ${ }^{3}$

Essam Morkos, ${ }^{3}$ Vidyanand Vaidya, ${ }^{3}$ Zeyana Al-Habsi, ${ }^{1}$ Idris Al-Abaidani, ${ }^{\text {* }}$ Seif S. Al-Abri ${ }^{2}$

\section{HIV المعرفة والمواقف والممارسات المرتبطة بوصمة الإصابة بفيروس الأيدز

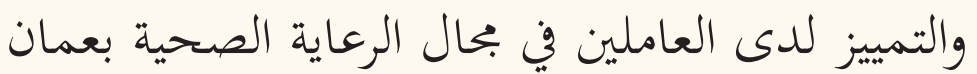

سمير شاه، علي الجالب، عادل الوهيبي، مها الفوري، براسنا راجو، محمود السكيتي، هدى نصيب المعشني، كيشور دوثادي، إياد عمر، محمد مقيت الل،

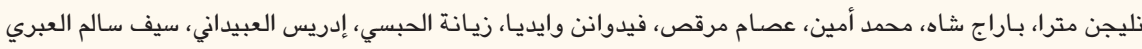

ABSTRACT: Objectives: Stigma and discrimination undermine the quality of life of people with HIV and their access to health services. This study aimed to assess HIV-related knowledge, attitudes and practices among healthcare workers (HCWs) in Oman. Methods: This cross-sectional study took place between July and November 2016. A questionnaire was distributed to 1,400 government HCWs to determine HIV-related knowledge, attitudes and practices. Results: A total of 1,281 HCWs participated (response rate $=92 \%$ ). Routine tasks, such as dressing wounds, drawing blood and touching clothes, were a cause of concern for $24-52 \%$ of HCWs. Only $69 \%$ correctly answered questions regarding the transmission of HIV via eating/drinking and mosquito bites. Compared to other HCWs, doctors had significantly higher knowledge $($ mean $=0.46,95 \%$ confidence interval $[\mathrm{CI}]: 0.19$ to $0.73 ; P<0.001)$, attitude (mean $=0.77,95 \% \mathrm{CI}$ : 0.31 to $1.24 ; P=0.001$ ) and practice (mean $=2.07,95 \%$ CI: 1.59 to $2.55 ; P<0.001)$ scores. Expatriates also scored significantly higher in knowledge (mean $=1.08,95 \%$ CI: 0.93 to $1.23 ; P<0.001$ ), attitude (mean $=1.23,95 \%$ CI: 0.98 to $1.48 ; P<0.001$ ) and practice (mean $=1.08,95 \%$ CI: 0.82 to $1.34 ; P<0.001$ ) compared to Omani nationals. Finally, those with $>15$ years' work experience scored significantly higher on knowledge (mean $=-0.60,95 \% \mathrm{CI}:-1.12$ to $-0.08 ; P=0.025$ ) and attitude (mean $=-0.99,95 \%$ CI: -1.87 to $-0.10 ; P=0.029)$ compared to those with less experience. Conclusion: The high rate of HIV-related stigma among HCWs in Oman should be rectified in order to achieve the 90-90-90 target set by the Joint United Nations Programme on HIV/AIDS.

Keywords: HIV; Social Stigma; Social Discrimination; Knowledge; Attitude; Professional Practice; Healthcare Providers; Oman.

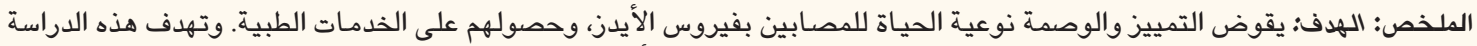

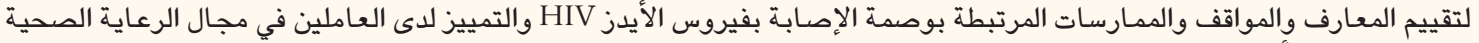

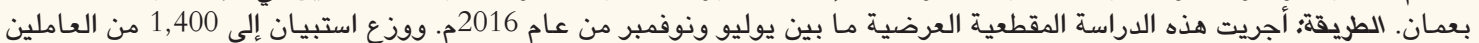

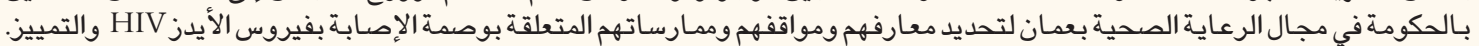

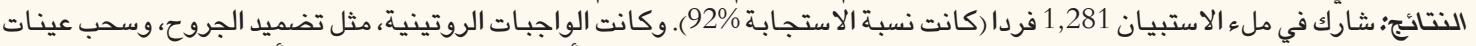

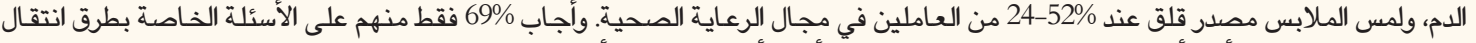

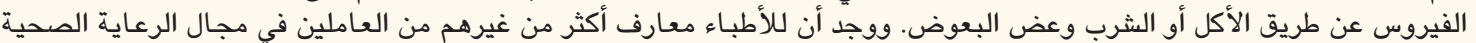

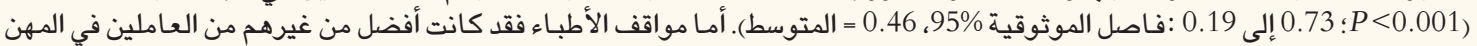

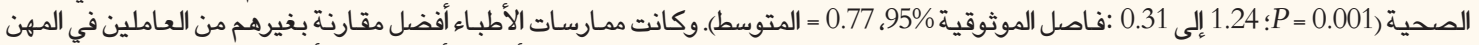

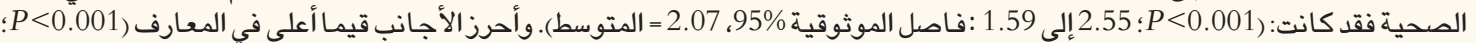

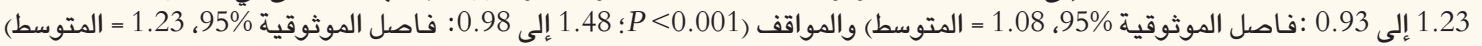

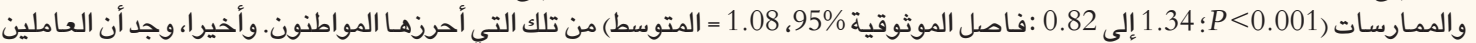

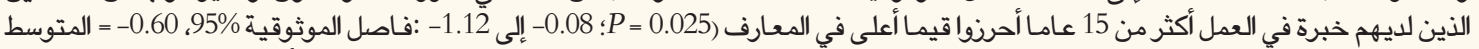

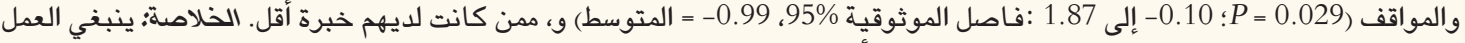

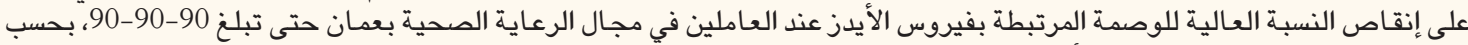

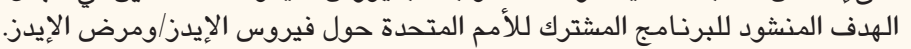

الكلمات المفتاحية: الوصمة الاجتماعية؛ التمييز الاجتماعي؛ المعارف؛ المواقف؛ الممارسات المهنية؛ مقدمو الرعاية الصحية؛ عمان. 
AdVANCES IN KNOWLEDGE

The findings of this study reveal HIV-related knowledge, attitudes and practices among governmental healthcare workers in Oman.

\section{Application to Patient Care}

The present study forms a basis for future initiatives to reduce discrimination in healthcare settings, in turn enhancing patient care and improving the quality of life of people living with HIV.

A $S$ PER THE JOINT UNITED NATIONS (UN) Programme on HIV/AIDS (UNAIDS), HIV stigma is the "process of devaluation" of people living with HIV, compounded by negative associations attached to the two primary methods of HIV transmission (i.e. sexual intercourse and intravenous drug use). ${ }^{1}$ Subsequently, stigma may result in active discrimination, defined as "the unfair and unjust treatment of an individual based on his or her real or perceived HIV status". ${ }^{1}$ Overall, negative judgements and actions towards people living with HIV tend to stem from pre-existing beliefs regarding gender, sexuality, race and class within a broader social context. ${ }^{2}$

Elements of stigma and discrimination can seriously undermine quality of life (QOL) and can create barriers to accessing and adhering to essential HIV services, both for people living with HIV and high-risk populations. ${ }^{3-5}$ Many deficiencies in HIV prevention, testing and treatment services are due to the stigma associated with the disease shown by healthcare workers themselves. ${ }^{6}$ In health settings, stigma and discrimination compromises the provision and quality of care, which is critical for helping patients adhere to medications and maintain overall health and well-being. ${ }^{5}$ This study aimed to assess HIV-related knowledge, attitudes and practices among governmental healthcare workers in Oman.

\section{Methods}

This cross-sectional study was conducted from July to November 2016 and targeted healthcare workers employed in the governmental health sector in Oman. Doctors, nurses, counsellors, pharmacists and other healthcare workers at Ministry of Health institutions were invited to participate in the study; however, specialists working at specialised HIV treatment centres were excluded. Based on an estimated total population of 33,000 governmental healthcare workers, the necessary sample size was calculated to be 1,034 at a 95\% confidence level and confidence interval of three. ${ }^{7}$ Presuming a 75\% response rate, 1,400 participants were recruited.

Participants were asked to complete a previously validated English-language questionnaire to measure HIV-related stigma and discrimination. ${ }^{8-11}$ Specifically, the questionnaire measured attitudes and practices towards people living with HIV in health services, school and the community, as well as stigma related to the ideas of people living with HIV getting married and having children. In addition, in order to assess basic knowledge of HIV, the UN's standardised five-item HIV awareness questionnaire was incorporated into the survey. ${ }^{11,12}$ The final questionnaire was tested in a pilot study of 50 healthcare workers, with no modifications subsequently deemed necessary. Accordingly, 1,400 copies of the questionnaire were distributed at all government health institutes in the country.

Initial data were collected and entered into a centrally-created data structure for each governorate, after which the data were cleaned, verified and compiled into a national database. Data entry and analysis were performed using an Excel spreadsheet, Version 2013 (Microsoft Corp., Redmond, Washington, USA) and $\mathrm{R}$ software (R Foundation for Statistical Computing, Vienna, Austria).

Categorical responses were presented as frequencies and percentages. In addition, responses to knowledge, attitude and practice questions were scored using a scaled-scoring method, with correct or positive responses given a score of one and incorrect and negative or missing responses given a score of zero. Questions with four responses (i.e. not worried, a little worried, worried and very worried) were given a score out of four according to the acceptability of the answer. Thereafter, the knowledge, attitude and practice scores were summed up for a total score.

Mean total knowledge, attitude and practice scores were analysed using multivariate linear regression. This allowed for comparison of the effect size (i.e. estimate of contrast) between groups, after controlling for other variables, and was used to examine the relationship between knowledge, practice and attitude scores and other characteristics. The regression was based on the presence or absence of various factors which were converted into 'dummy' variables and were scored as one if present and zero if absent. Pearson's correlation coefficient was used to determine correlations between knowledge and attitude scores, attitude and practice scores and knowledge and practice scores. The level of statistical significance was set at $P<0.05$.

This study received ethical approval and was registered with the Directorate General for Disease Surveillance \& Control, Ministry of Health. Participation in the study was purely voluntary and all data were collected anonymously. 
Table 1: Sociodemographic characteristics of governmental healthcare workers in Oman $(\mathrm{N}=1,281)$

\begin{tabular}{|c|c|c|c|}
\hline \multirow[t]{2}{*}{ Characteristic } & \multicolumn{3}{|c|}{ n (\%) } \\
\hline & Total & $\begin{array}{c}\text { Male } \\
(\mathbf{n}=392)\end{array}$ & $\begin{array}{c}\text { Female } \\
(\mathbf{n}=889)\end{array}$ \\
\hline \multicolumn{4}{|l|}{ Nationality } \\
\hline Omani & $669(52)$ & $128(33)$ & $541(61)$ \\
\hline Expatriate $^{*}$ & $574(45)$ & $256(65)$ & $318(36)$ \\
\hline Unknown & $38(3)$ & $8(2)$ & $30(3)$ \\
\hline \multicolumn{4}{|l|}{ Marital status } \\
\hline Married & $1,050(82)$ & 337 (86) & $713(80)$ \\
\hline Single & 204 (16) & $51(13)$ & $153(17)$ \\
\hline $\begin{array}{l}\text { Previously } \\
\text { married }\end{array}$ & 14. (1) & $1(<1)$ & $13(1)$ \\
\hline Unknown & $13(1)$ & $3(1)$ & $10(1)$ \\
\hline \multicolumn{4}{|l|}{ Profession } \\
\hline Staff nurse & $594(46)$ & $63(16)$ & $531(60)$ \\
\hline Doctor & $317(25)$ & $175(45)$ & $142(16)$ \\
\hline Pharmacist & $131(10)$ & $54(14)$ & $77(9)$ \\
\hline $\begin{array}{l}\text { Laboratory } \\
\text { technician }\end{array}$ & $98(8)$ & 44. (11) & $54(6)$ \\
\hline Other $^{\dagger}$ & $103(8)$ & $48(12)$ & $55(6)$ \\
\hline Unknown & $38(3)$ & $8(2)$ & $30(3)$ \\
\hline \multicolumn{4}{|c|}{$\begin{array}{l}\text { "Including Indians, Filipinos, Egyptians, Sudanese, Pakistanis, Tunisians, } \\
\text { etc. Including counsellors, physiotherapists, dental technicians, dieticians } \\
\text { X-ray technicians, health educators, refractionists, medical orderlies, etc. }\end{array}$} \\
\hline Results & & & \\
\hline
\end{tabular}

A total of 1,281 healthcare workers participated in the study (response rate $=92 \%$ ). Of these, $52 \%$ were Omani nationals and $82 \%$ were married. The majority were staff nurses (46\%), followed by doctors $(25 \%)$, pharmacists $(10 \%)$, laboratory technicians $(8 \%)$ and other workers (8\%) [Table 1]. Regarding knowledge, there was varying awareness of HIV symptoms and transmission patterns. While $74 \%$ were aware that the use of a condom mitigated the risk of contracting HIV and $86 \%$ knew that HIV patients were of generally healthy appearance, only 69\% correctly answered questions regarding the transmission of HIV via eating/drinking and mosquito bites [Table 2].

With regards to attitude, 50\% of healthcare workers reported that they would not want to buy fresh vegetables from a vendor living with HIV. Moreover, 39\% believed that people talk badly about individuals thought to be living with HIV and $41 \%$ thought that such individuals lose respect or stature in the community. As for marital and reproductive rights, $52 \%$ and $45 \%$ indicated that people living with HIV should have the right to marry and have children, respectively [Table 3].
Table 2: Knowledge of HIV symptoms and transmission methods among governmental healthcare workers in Oman $(\mathrm{N}=1,281)$

\begin{tabular}{lc} 
Questionnaire item and response & n (\%) \\
Can having sex with only one faithful, uninfected partner \\
reduce the risk of HIV/AIDS transmission? \\
Yes & $714(56)$ \\
No & $229(18)$ \\
No answer* & $338(26)$ \\
Can using condoms reduce the risk of HIV/AIDS & \\
transmission? & \\
Yes & $942(74)$ \\
No & $159(12)$ \\
No answer* & $180(14)$ \\
Can a person who looks healthy have HIV/AIDS? & \\
Yes & $1,097(86)$ \\
No & $74(6)$ \\
No answer* & $110(9)$ \\
Can sharing a drinking glass or eating with an HIV/AIDS \\
patient transmit the infection? \\
Yes & $186(15)$ \\
No & $885(69)$ \\
No answer* & $210(16)$ \\
Can a person get HIV/AIDS from mosquito bites? & \\
Yes & $882(69)$ \\
No & $112(9)$ \\
No answer* & \\
\hline
\end{tabular}

*Participants preferred not to respond.

In terms of HIV-related practices, $27 \%$ of healthcare workers avoided physical contact when providing care/services to a person living with HIV, 24\% were worried or very worried about touching their clothing, $47 \%$ were worried or very worried about dressing wounds, $52 \%$ were worried or very worried about drawing blood and 55\% feared contracting HIV if they came into contact with their saliva [Table 4].

A multivariate linear regression analysis was carried out to determine associations between sociodemographic characteristics and mean knowledge, attitude and practice scores, after controlling for other variables. Compared to other healthcare professionals, doctors scored significantly higher in knowledge (mean $=0.46,95 \%$ CI: 0.19 to $0.73 ; P<0.001$ ), attitude (mean $=0.77,95 \% \mathrm{CI}: 0.31$ to $1.24 ; P=0.001$ ) and practice $($ mean $=2.07,95 \% \mathrm{CI}: 1.59$ to $2.55 ; P<0.001$ ). In addition, nurses had significantly higher practice scores compared to laboratory technicians and pharmacists (mean $=2.16,95 \%$ CI: 1.71 to $2.61 ; P<0.001)$. Pharmacists 
Table 3: Attitudes related to HIV among governmental healthcare workers in Oman $(\mathrm{N}=1,281)$

\begin{tabular}{|c|c|}
\hline Questionnaire item and response & n (\%) \\
\hline \multicolumn{2}{|c|}{$\begin{array}{l}\text { Do you think children living with HIV/AIDS should be able } \\
\text { to attend school with children who are HIV-negative? }\end{array}$} \\
\hline Yes & $959(75)$ \\
\hline No & $311(24)$ \\
\hline No answer* & $11(1)$ \\
\hline \multicolumn{2}{|c|}{$\begin{array}{l}\text { If a teacher has HIV/AIDS but is not sick, should he/she be } \\
\text { allowed to continue teaching in school? }\end{array}$} \\
\hline Yes & $1,024(80)$ \\
\hline No & 247 (19) \\
\hline No answer* & $10(1)$ \\
\hline \multicolumn{2}{|c|}{$\begin{array}{l}\text { If you knew that an Omani vegetable vendor had HIV/AIDS } \\
\text { would you buy fresh vegetables from him/her?† }\end{array}$} \\
\hline Yes & $614(48)$ \\
\hline No & $644(50)$ \\
\hline No answer* & $23(2)$ \\
\hline \multicolumn{2}{|c|}{$\begin{array}{l}\text { Do people talk badly about people living or thought to be } \\
\text { living with HIV/AIDS? }\end{array}$} \\
\hline Yes & $498(39)$ \\
\hline No & $301(23)$ \\
\hline No answer* & $482(38)$ \\
\hline
\end{tabular}

Do people living or thought to be living with HIV/AIDS lose respect or stature in the community?

Yes

No

$363(28)$

No answer*

$397(31)$

If a member of your family became infected with HIV/AIDS would you want it to remain a secret?

Yes

$982(77)$

No

No answer*

14. (1)

If a member of your family became sick with HIV/

AIDS, would you be willing to care for him or her in your household?

Yes

No

No answer*

Would you be ashamed if someone in your family had HIV AIDS?

Yes

$390(30)$

No

No answer*

Should people living with HIV/AIDS feel ashamed of themselves?

Yes

284 (22)

No

No answer

Should people living with HIV/AIDS have the right to marry? Yes

$669(52)$

No

$597(47)$

No answer*

$15(1)$

HCWS $=$ healthcare workers. *Participants preferred not to respond ${ }^{+}$Assuming that no municipality licence rules restrict the vendor from selling vegetables.
Table 3 (cont'd): Attitudes related to HIV among governmental healthcare workers in Oman $(\mathrm{N}=1,281)$

Questionnaire item and response $\quad \mathrm{n}(\%)$

Should people living with HIV/AIDS be allowed to have babies?

Yes

No

No answer*

In the past 12 months, have you observed any HCWs unwilling to care for people living with HIV/AIDS in your healthcare facility?

Yes

No

No answer*

HCWS = healthcare workers. "Participants preferred not to respond Assuming that no municipality licence rules restrict the vendor from selling vegetables.

Table 4: Practices related to people living with HIV among governmental healthcare workers in Oman $(\mathrm{N}=1,281)$

Questionnaire item and response

n (\%)

Do you avoid physical contact when providing care or services to a person living with HIV/AIDS?

Yes

No

No answer*

How worried would you be if you touched the clothing of a person living with HIV/AIDS?

Not worried

A little worried

Worried

Very worried

No answer*

How worried would you be if you had to dress the wound of a person living with HIV/AIDS?

Not worried

A little worried

Worried

Very worried

No answer"

$252(20)$

How worried would you be if you had to draw blood from a person living with HIV/AIDS?

Not worried

A little worried

Worried

Very worried

No answer*

190 (15)

Do you fear contracting HIV if you come in contact with the saliva of a person living with HIV/AIDS?

Yes

No

No answer*

*Participants either did not have direct patient care or preferred not to respond. 
Table 5: Associations between dependent variables and HIV-related knowledge, attitude and practice scores among governmental healthcare workers in Oman $(\mathrm{N}=1,281)$

\begin{tabular}{|c|c|c|c|c|c|c|}
\hline \multirow{2}{*}{ Variable } & \multicolumn{2}{|l|}{ Knowledge } & \multicolumn{2}{|l|}{ Attitude } & \multicolumn{2}{|l|}{ Practice } \\
\hline & Mean score (95\% CI) & $P$ value & Mean score $(95 \% \mathrm{CI})$ & $P$ value & Mean score $(95 \% \mathrm{CI})$ & $P$ value \\
\hline Doctor & $0.46(0.19$ to 0.73$)$ & $<0.001^{*}$ & $0.77(0.31$ to 1.24$)$ & $0.001^{*}$ & 2.07 (1.59 to 2.55$)$ & $<0.001^{*}$ \\
\hline Laboratory technician & $0.14(-0.19$ to 0.46$)$ & 0.398 & $0.60(0.05$ to 1.16$)$ & $0.033^{*}$ & $0.16(-0.41$ to 0.74$)$ & 0.582 \\
\hline Pharmacist & $-0.30(-0.61$ to 0.00$)$ & $0.049^{*}$ & $0.17(-0.35$ to 0.68$)$ & 0.523 & $-0.11(-0.64$ to 0.43$)$ & 0.694 \\
\hline \multicolumn{7}{|l|}{ Gender } \\
\hline Non-Omani & 1.08 (0.93 to 1.23$)$ & $<0.001^{*}$ & 1.23 (0.98 to 1.48$)$ & $<0.001^{*}$ & 1.08 (0.82 to 1.34$)$ & $<0.001^{*}$ \\
\hline \multicolumn{7}{|l|}{ Years of experience } \\
\hline$<5$ & $-0.32(-0.84$ to 0.21$)$ & 0.233 & $-0.76(-1.65$ to 0.13$)$ & 0.095 & $-0.26(-1.19$ to 0.67$)$ & 0.584 \\
\hline $5-15$ & $-0.32(-0.82$ to 0.19$)$ & 0.224 & $-0.64(-1.5$ to 0.23$)$ & 0.149 & $-0.41(-1.31$ to 0.49$)$ & 0.372 \\
\hline$>15$ & $\begin{array}{c}-0.60(-1.12 \text { to } \\
-0.08)\end{array}$ & $0.025^{*}$ & $-0.99(-1.87$ to -0.10$)$ & $0.029^{*}$ & $-0.50(-1.43$ to 0.42$)$ & 0.284 \\
\hline \multicolumn{7}{|l|}{ Marital status } \\
\hline
\end{tabular}

had the lowest scores for knowledge (mean $=-0.30$, 95\% CI: -0.61 to 0.00 ), attitude (mean $=0.17,95 \%$ CI: -0.35 to 0.68$)$ and practice (mean $=-0.11,95 \%$ CI: -0.64 to 0.43$)$.

Compared to Omani nationals, expatriates scored significantly higher in knowledge (mean $=1.08,95 \%$ CI: 0.93 to $1.23 ; P<0.001$ ), attitude (mean $=1.23,95 \%$ CI: 0.98 to $1.48 ; P<0.001$ ) and practice (mean $=1.08$, 95\% CI: 0.82 to $1.34 ; P<0.001$ ). Finally, those with $>15$ years' work experience had significantly greater scores for knowledge $($ mean $=-0.60,95 \% \mathrm{CI}:-1.12$ to $-0.08 ; P=0.025$ ) and attitude (mean $=-0.99,95 \%$ CI: -1.87 to $-0.10 ; P=0.029)$ compared to those with less experience [Table 5]. Positive linear correlations were noted between knowledge and attitude $(r=0.26)$, attitude and practice $(r=0.28)$ and knowledge and practice $(r=0.20)$, with all three correlations being statistically significant $(P<0.05$ each).

\section{Discussion}

According to the classifications of the World Health Organization, the HIV epidemic in Oman is at a low level. ${ }^{13,14}$ This is in part due to the efforts of the national AIDS programme established in 1987 and various other measures, including community awareness and regular HIV testing and treatment. In addition, HIV services are provided by 14 specialised treatment centres located across the country. As of the end of 2018, a total of 3,025 cases of HIV had been reported, of which 1,532 (50.6\%) were still living. ${ }^{15}$ Most cases occurred among men (68\%) and individuals aged 25-44 years old (59\%); the greatest risk factor was reportedly heterosexual relations (66\%). ${ }^{15}$ In terms of treatment, $84.3 \%$ of people living with HIV received antiretroviral therapy, with $87.5 \%$ virally suppressed. ${ }^{15}$

Nevertheless, despite the low prevalence of HIV and the availability of treatment, there is still social stigma towards people living with HIV in Oman. In a study of 193 people living with HIV in Oman, 70\% were unwilling to disclose their HIV status to their friends and family, while $61 \%$ were uncomfortable at the prospect of doing so. ${ }^{16}$ The majority (61\%) reported relying on their family for financial and emotional support; this is to be expected in a society where cultural traditions consider family to be of paramount importance. Despite the availability of social services, many did not accept government assistance, with 75\% claiming fears of a breach of privacy as the primary reason for not doing so. ${ }^{16}$ 
The current study noted a relatively high rate of HIV-related stigma among healthcare workers in the country. A national survey of households in Thailand found that $52.1 \%$ of respondents would refuse to buy fresh food from a vendor if they knew that the seller had HIV. ${ }^{17}$ As the same response was given by $50 \%$ of healthcare workers in the current study, this prejudicial attitude is likely to be even more prevalent in the Omani community. Indeed, discriminatory attitudes may be much more common among members of the general public, given that $39 \%$ and $41 \%$ of the healthcare workers believed that other people would talk negatively of those living with HIV and that affected individuals would lose respect or stature in the community, respectively.

In the current study, there were relatively good levels of knowledge regarding the use of condoms for HIV prevention (74\%) and that people living with HIV often appear healthy (86\%). However, knowledge was below expectations regarding HIV transmission methods (69\%). A much higher percentage (94.5\%) of 200 final-year medical students in Vietnam were aware of the usage of condoms for HIV prevention. ${ }^{18}$ Moreover, 24-54\% of healthcare workers in the present study were either worried or very worried about performing various day-to-day duties for patients living with HIV. This finding is comparable to other research; in Thailand, $32-66 \%$ of 738 healthcare providers were worried about similar duties, while $23-67 \%$ of more than 1,000 healthcare workers from multiple countries were similarly concerned. ${ }^{8,19}$

Stigma often leads to the avoidance of duties. In the present study, 9\% of healthcare workers reported having observed others in their institution being unwilling to care for people living with HIV. A study of 922 nurses in Jordan found that $84 \%$ of nurses refused to provide care to patients who tested positive for HIV/ AIDS. ${ }^{20}$ Another study from Egypt reported that $72.3 \%$ of 65 nurses avoided providing care to patients with HIV/AIDS. ${ }^{21}$ In a multinational study conducted in 15 countries and involving more than 1,000 healthcare workers, this statistic ranged from $23-30 \% .{ }^{8}$ However, in a study from Italy of 107 hospital nurses with good knowledge about HIV, only $2 \%$ refused to care for patients based on their HIV status. ${ }^{22}$ Another study of 450 healthcare practitioners in India found that only $4.1 \%$ wished they were allowed to refuse to care for people with HIV/AIDS. ${ }^{23}$

In the present study, HIV-related knowledge, attitudes and practices were associated with profession; doctors had significantly greater knowledge, attitude and practice scores compared to other healthcare workers, while nurses had better practice scores compared to laboratory technicians and pharmacists. The latter finding might be explained in part by differences in professional duties, with nurses expected to be more 'hands on' in terms of patient care compared to other paramedical professions. In addition, the current study observed significantly higher mean knowledge, attitude and practice scores among expatriates. The exact reason for this result is unknown; however, the authors postulate that it may be because of educational and cultural differences. Finally, the present study also showed that more years of work experience yielded significantly higher knowledge and attitude scores.

It is a basic human right to choose to marry and/or have children, regardless of HIV status. ${ }^{24}$ However, $47 \%$ and $53 \%$ of healthcare workers in the present study did not agree with the idea of such individuals having the right to marry and procreate, respectively. Similar findings were reported in a study in India, whereby $41 \%$ and $37 \%$ of 305 doctors, $77 \%$ and $73 \%$ of 369 nurses and $88 \%$ and $86 \%$ of 346 ward staff believed that men and women, respectively, with HIV should be forbidden to marry. ${ }^{25}$ In a multinational study of over 1,000 healthcare workers, $40 \%$ were against people living with HIV having the right to procreate. ${ }^{8}$

The positive three-way correlation between knowledge, attitude and practice suggests that improving any one of these factors will have a positive impact on the other two. The findings of the current study have various implications, as they clearly demonstrate the need for more HIV-related interactive training for all healthcare workers in Oman. Such training is also recommended by UNAIDS to help reduce stigma and discrimination for people living with HIV. ${ }^{6}$ In addition, an HIVrelated stigma and discrimination awareness module should be incorporated into the undergraduate and postgraduate curriculum of all health science degrees. Finally, further research is needed to better understand the nature of HIV-related stigma and discrimination, both among healthcare workers and in the general community. Such measures will help reduce HIVrelated stigma and discrimination in the healthcare system in Oman, a crucial requirement if the country aimed to achieve the 90-90-90 target set by UNAIDS by $2020 .{ }^{26}$

The strengths of this study lie in the nationwide participation of healthcare institutions and the large sample size involving a variety of healthcare professionals. In addition, the sample was fairly representative as every government health sector in Oman was given the opportunity to participate in the study. However, there were several limitations. The non-response bias was not measured; as participation was voluntary, it is likely that those who agreed to participate already held strong opinions on the topic. Moreover, the study assessed only healthcare workers employed in the government 
sector, with variable responses across governorates. As such, those working in the private sector may have very different views and attitudes. In addition, the present study could not explain reasons for higher mean scores among expatriates compared to nationals; further study into this finding is necessary. Furthermore, like most other questionnaire-based studies, results in the present analysis may have been affected by response bias.

\section{Conclusion}

There was a high level of HIV-related stigma among healthcare workers in the governmental health sector in Oman. As such, measures to increase knowledge and support positive attitudes and practices should be implemented at all levels of the healthcare system, geared particularly towards Omani nationals. Such initiatives are necessary if the country is to meet the 90-90-90 target set by UNAIDS.

\section{CONFLICT OF INTEREST}

The authors declare no conflicts of interest.

\section{FUNDING}

No funding was received for this study.

\section{References}

1. Joint United Nations Programme on HIV/AIDS. Fact sheet: Stigma and discrimination. From: http://data.unaids.org/publi cations/fact-sheets03/fs_stigma_discrimination_en.pdf Accessed: Sep 2019.

2. Parker R, Aggleton P. HIV and AIDS-related stigma and discrimination: A conceptual framework and implications for action. Soc Sci Med 2003; 57:13-24. https://doi.org/10.1016/ S0277-9536(02)00304-0.

3. Banteyerga H, Kidanu A, Abebe F, Alemayehu M, Fiseha B, Asazenew A, et al. Perceived stigmatization and discrimination by health care providers towards persons with HIV/AIDS Chapel Hill, North Carolina, USA: IntraHealth International Inc., 2005. https://doi.org/10.13140/2.1.3556.7687.

4. Feyissa GT, Abebe L, Girma E, Woldie M. Stigma and discrimination against people living with HIV by healthcare providers, Southwest Ethiopia. BMC Public Health 2012; 12:522. https://doi.org/10.1186/1471-2458-12-522.

5. Piot P. How to reduce the stigma of AIDS: Keynote address Symposium at the XVI International AIDS Conference. From: http://data.unaids.org/pub/speechexd/2006/200608012_sp_ piot_stigma-speech_en.pdf Accessed: Sep 2019.

6. Joint United Nations Programme on HIV/AIDS. Confronting discrimination: Overcoming HIV-related stigma and discrimination in health-care settings and beyond. From: www.unaids.org/sites/default/files/media_asset/confrontingdiscrimination_en.pdf Accessed: Sep 2019.

7. Ministry of Health Oman. Annual health report 2017: Chapter four - Human resources for health. From: www.moh.gov.om/ en/web/statistics/-/20-52 Accessed: Sep 2019.
8. Nyblade L, Jain A, Benkirane M, Li L, Lohiniva AL, McLean R, et al. A brief, standardized tool for measuring HIV-related stigma among health facility staff: Results of field testing in China, Dominica, Egypt, Kenya, Puerto Rico and St. Christopher \& Nevis. J Int AIDS Soc 2013; 16:18718. https://doi. org/10.7448/IAS.16.3.18718.

9. Srithanaviboonchai K, Stockton M, Pudpong N, Chariyalertsak S, Prakongsai $\mathrm{P}$, Chariyalertsak $\mathrm{C}$, et al. Building the evidence base for stigma and discrimination-reduction programming in Thailand: Development of tools to measure healthcare stigma and discrimination. BMC Public Health 2017; 17:245. https:// doi.org/10.1186/s12889-017-4172-4.

10. Health Policy Project. Measuring HIV stigma and discrimination among health facility staff: Standardized brief questionnaire. From: www.healthpolicyproject.com/pubs/49_Standardi zedBriefQuestionnaireMeasuringSD.pdf Accessed: Sep 2019.

11. Multiple Indicator Cluster Survey Programme. Questionnaire for individual women. From: https://microdata.worldbank.org/ index.php/catalog/10/download/84 Accessed: Sep 2019.

12. Joint United Nations Programme on HIV/AIDS. Global AIDS response progress reporting 2016: Construction of core indicators for monitoring the 2011 United Nations Political Declaration on HIV and AIDS. From: https://aidsreportingtool. unaids.org/static/docs/GARPR_Guidelines_2016_EN.pdf Accessed: Sep 2019.

13. World Health Organization. Definition of key terms: Consolidated ARV guidelines, June 2013. From: www.who.int/ hiv/pub/guidelines/arv2013/intro/keyterms/en/ Accessed: Sep 2019.

14. Joint United Nations Programme on HIV and AIDS. UNAIDS Data 2019. From: www.unaids.org/sites/default/files/media asset/2019-UNAIDS-data_en.pdf Accessed: Feb 2020.

15. Elgalib A, Shah S, Al-Habsi Z, Al-Fouri M, Lau R, Al-Kindi H, et al. The cascade of HIV care in Oman, 2015-2018: A population-based study from the Middle East. Int J Infect Dis 2020; 90:28-34. https://doi.org/10.1016/j.ijid.2019.09.017.

16. Ministry of Health, Oman. Study on the needs of the PLHIV and their caregivers in the Sultanate of Oman [personal communication]. Muscat, Oman, 2012.

17. Srithanaviboonchai K, Chariyalertsak S, Nontarak J, Assanangkornchai S, Kessomboon P, Putwatana P, et al. Stigmatizing attitudes toward people living with HIV among general adult Thai population: Results from the 5th Thai National Health Examination Survey (NHES). PLoS ONE 2017; 12:e0187231. https://doi.org/10.1371/journal.pone.0187231.

18. Platten M, Pham HN, Nguyen HV, Nguyen NT, Le GM. Knowledge of HIV and factors associated with attitudes towards HIV among final-year medical students at Hanoi medical university in Vietnam. BMC Public Health 2014; 14:265. https://doi.org/10.1186/1471-2458-14-265.

19. International Health Policy Program, Thailand Ministry of Public Health. Report of a pilot: Developing tools and methods to measure HIV-related stigma and discrimination in health care settings in Thailand. Nonthaburi, Thailand: International Health Policy Program, 2014.

20. Hassan ZM, Wahsheh MA. Knowledge and attitudes of Jordanian nurses towards patients with HIV/AIDS: Findings from a nationwide survey. Issues Ment Health Nurs 2011; 32:774-84. https://doi.org/10.3109/01612840.2011.610562.

21. Magdi HM, Abd El-Fatah SR, Nawal AA, Afefe AH. Knowledge, attitudes and practice of nurses working with HIV/AIDS patients. Egypt J Health Care 2013; 4:1-14.

22. Marranzano M, Ragusa R, Platania M, Faro G, Coniglio MA. Knowledge, attitudes and practices towards patients with HIV/AIDS in staff nurses in one university hospital in Sicily. Epidemiol Biostat Public Health 2013; 10:e8731-1-6. https://doi.org/10.2427/8731. 
23. Yadav SS, Yadav S, Mishra P. Knowledge and risk perception regarding HIV among healthcare workers in a medical college hospital. Int J Med Sci Public Health 2014; 3:73-5. https://doi. org/10.5455/ijmsph.2013.051020131.

24. Global Network of People Living with HIV/AIDS. Advancing the sexual and reproductive health and human rights of people living with HIV: A guidance package. From: www.unfpa. org/sites/default/files/resource-pdf/guidance_package.pdf Accessed: Sep 2019.
25. Ekstrand ML, Ramakrishna J, Bharat S, Heylen E. Prevalence and drivers of HIV stigma among health providers in urban India: Implications for interventions. J Int AIDS Soc 2013; 16:18717. https://doi.org/10.7448/IAS.16.3.18717.

26. Joint United Nations Programme on HIV/AIDS. 90-90-90: An ambitious treatment target to help end the AIDS epidemic. From: https://www.unaids.org/sites/default/files/media_asset/ 90-90-90_en.pdf Accessed: Sep 2019. 